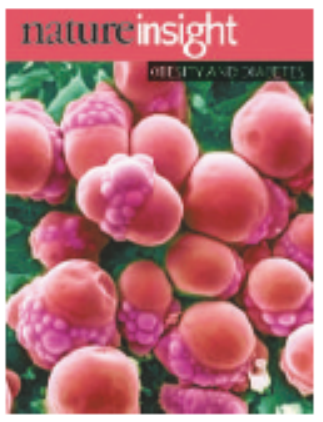

Cover illustration Coloured scanning electran micrograph of adipocytes (pirk) from bone-marrow tissue. (Courtesy of Science Photo Library.)

\section{Editor, Nature Philip Campbell Insights Publisher Sarah Greaves Insights Editor Lesley Anson} Commissioning Editor Rary Howlett

\section{Production Editor} Sarah Archibald

Senior Art Editor Martin Harrison

Art Editor

Nik Spencer

Sponsorship Claire Hines Claudia Banks

Production Susan Gray Marketing Katy Dunningham

EditorialAssistant Laura Shaw

\title{
OBESITY AND DIABETES
}

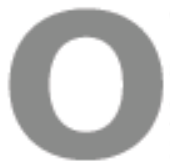
besity and type 2 diabetes represent a serious threat to the health of the population of almost every country in the world. The World Health

Organization estimates that 1.1 million people died as a result of diabetes in 2005, and this is almost certainly an underestimate. Moreover, the figure is expected to increase by $50 \%$ during the next ten years.

This escalation is due in part to increasing rates of childhood obesity. Until recently, type 2 diabetes was a disease that afflicted only adults. Now a growing number of children are being diagnosed with obesityrelated type 2 diabetes. Also increasing is the incidence of 'metabolic syndrome' - a complex condition linked to obesity that is characterized by a cluster of closely related clinical features, including insulin resistance, dyslipidaemia and hypertension. Metabolic syndrome is associated with an increased risk of cardiovascular disease, which is ultimately responsible for a considerable proportion of diabetic mortality.

There is, therefore, an urgent need for new approaches to address obesity and type 2 diabetes and their associated complications. In particular, understanding the various processes that give rise to the characteristics of metabolic syndrome and its attendant risks - from abnormal regulation of energy metabolism through to dysfunction of molecular mechanisms - will pave the way for the development of new treatment strategies. And, as the reviews in this Insight highlight, it is hoped that a combination of preventative and therapeutic strategies will ultimately reduce the burden of type 2 diabetes on society.

We are pleased to acknowledge the support of Nestlé Research Center in producing this Insight. As always, Nature carries sole responsibility for all editorial content and peer review.

Deepa Nath, Marie-Thérèse Heemels and Lesley Anson, Senior Editors

\section{REVIEWS}

840 Mechanisms linking obesity to insulin resistance and type 2 diabetes
S. E. Kahn, R. L. Hull \&
K. M. Utzschneider

847 Adipocytes as regulators of energy balance and glucose homeostasis

E. D. Rosen \& B. M. Spiegelman

854 Gut hor mones and the regulation of energy homeostasis

K. G. Murphy \& S. R. Bloom

860 Inflammation and metabolic disorders
G. S. Hotamisligil

868 Sirtuins as potential targets for metabolic syndrome

L. Guarente

875 Mechanisms linking obesity with cardiovascular disease

L. F. Van Gaal, I. L. Mertens \& C.E. De Block

881 Abdominal obesity and metabolic syndrome J.-P. Després \& I. Lemieux

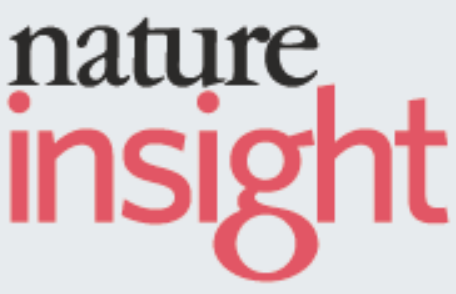

